\title{
Concerning the Use of Doppler and 3-D Ultrasound in the Teaching of Gross Anatomy in a New Curriculum Featuring the Use of Clinical Presentation Schemes
}

\author{
${ }^{1}$ Asa C Black (Jr), ${ }^{2}$ Sanja Plavsic Kupesic \\ ${ }^{1}$ Professor of Gross and Neuroanatomy, Department of Medical Education, Paul L Foster School of Medicine, 5001 El Paso \\ Drive, El Paso, Texas 79905, USA \\ ${ }^{2}$ Professor and Clinical Professor of Obstetrics and Gynecology and Radiology, Department of Medical Education, Paul L \\ Foster School of Medicine, Texas Tech University Health Sciences Center, 5001 El Paso Drive, EI Paso, Texas 79905, USA
}

Correspondence: Asa C Black (Jr), Professor of Gross and Neuroanatomy, Department of Medical Education, Paul L Foster School of Medicine, 5001 El Paso Drive, El Paso, Texas 79905, USA, Phone: (915)-783-1700 Ext. 251, Fax: (915)_783-1709 e-mail: asa.c.black@ttuhsc.edu

\begin{abstract}
Although gross anatomical instruction has always been considered a foundation for medical education and practice, curricular changes have altered the manner in which it is taught. The integration of basic biomedical sciences began with the case-western reserve curriculum. Under the leadership of Dr. Henry Mandin, the University of Calgary School of Medicine developed a program of medical instruction based on 120 clinical presentation schemes. The Paul L Foster School of Medicine is currently using this approach in teaching its first class of freshman medical students.

Three-dimensional ultrasound and the other visual modalities—radiography, computerized tomography (CT) and magnetic resonance imaging (MRI)—have greatly increased our ability to visualize anatomical structures. Three-dimensional ultrasound has great potential for use in the curriculum at Paul L Foster School of Medicine. For example, it can help the student differentiate between the varieties of pelvic mass, which can be subdivided into ovarian, tubal, and uterine causes. This paper demonstrates the ways that Doppler threedimensional ultrasound can help the student differentiate between these anatomical diagnoses. Coupling ultrasound with the histopathologic study of various lesions can provide a powerful visual learning tool that mimics the use of these techniques in a clinical setting.
\end{abstract}

Keywords: Gross anatomy, curriculum, Doppler ultrasound, three-dimensional ultrasound, pelvic mass.

\section{INTRODUCTION}

Gross anatomical instruction has undergone many changes in the preceding half century. It was originally taught as the "queen of the basic medical sciences" as a fundamental course basic to medical education. Contact times of 250 hours in a semester were the norm. Radiological instruction has always been part of this picture.

Curricular change began in earnest in the 1960s. Prior to this time, the curriculum at case-western reserve medical school was unique in that it aimed at organizing the curriculum by organ systems. In this approach, the student studied concurrently all the basic sciences pertinent to an organ system such as the cardiovascular system in an integrated manner.

Curricular pressures have tended to force a decrease in the number of hours devoted to laboratory instruction in gross anatomy. The advent of problem-based curricula in the 1980s forced further fundamental changes in gross anatomy instruction. ${ }^{1}$ In these PBL and integrated curricula, gross anatomy was sometimes taught early in the first year rather than being integrated into the curriculum. More often, gross anatomical instruction was spread throughout the two years of basic science instruction. This posed great challenges in the instruction of gross anatomy, especially in the laboratory component. There was a concomitant movement to use modern radiologic techniques such as MRI, CT, and ultrasound to augment the teaching of traditional gross anatomical material in addition to the use of cadavers-whether dissected or prosected.

\section{THE PAUL L FOSTER SCHOOL OF MEDICINE CURRICULUM}

The curriculum at the Paul L Foster School of Medicine is based on the curriculum at the University of Calgary, Canada. 
This curriculum features 120 clinical presentation schemes that represent patterns of expert thinking regarding commmon symptoms such as chest discomfort. At Paul L Foster School of Medicine, the week begins with the clinical presentation scheme which features the possible disease states involved in such a symptom. The rest of the week is devoted to the basic sciences required to understand various aspects of the scheme. On Friday morning, clinicians present analyses of actual cases of the diseases pertinent to the topic of the scheme. This approach is based on work of Henry Mandin and his colleagues at the University of Calgary, which originally had an organ system-based curriculum patterned after that of case-western reserve school of medicine. ${ }^{2}$ However, in 1994 the school adopted the clinical presentation curriculum, and today it represents the chief exponent of this advanced form of integrated and clinically-relevant curriculum. Figure 1 presents a scheme for pelvic mass, which is typical of the clinical presentation schemes.

\section{USE OF TWO-DIMENSIONAL ULTRASOUND IN GROSS ANATOMY INSTRUCTION}

Two-dimensional ultrasound has had an important role in medical practice for years. ${ }^{3,4}$ However, its utility in gross anatomical instruction has been somewhat limited by the two-dimensional nature of the images. Where it has been possible to actually have the students use an ultrasound machine as part of their gross anatomical instruction, this has been helpful. However, the two-dimensional nature of the images has limited their use in lectures or other formats. To be blunt, one often has had to know the location of the transducer producing the image in order to understand the image. By contrast, one often needs no description of the location of the tissues being imaged on an MRI or CT in order to understand them.

The development of three-dimensional ultrasound has ameliorated this limitation. Figure 2 compares two- and three-dimensional ultrasound images of a polycystic ovary. ${ }^{5}$ Frequently the images available with three-dimensional ultrasound are fully developed and complete enough to use as stand-along images in a lecture or as part of a panel in the laboratory. They can also be featured as a component of a Powerpoint presentation.

\section{ULTRASOUND AS A MEANS OF EXPLORING THE CLINICAL PRESENTATION SCHEMES}

The clinical presentation scheme for pelvic mass is presented in Figure 1. The first point on the decision tree in this clinical

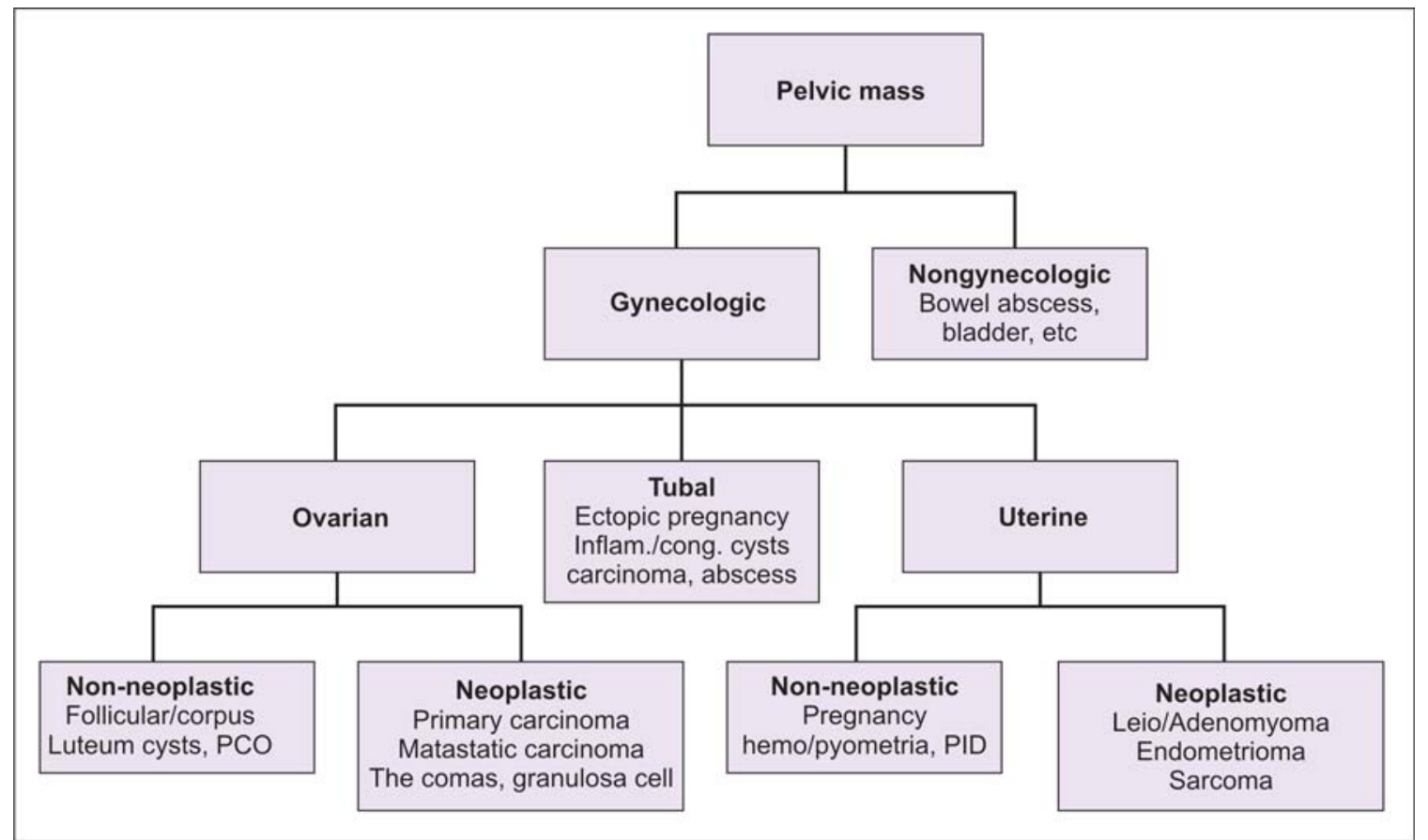

Fig. 1: Clinical presentation scheme for pelvic mass. Note the division into gynecologic and nongynecologic pathology. This scheme is a part of the reproduction unit, so the nongynecologic schemes are not pursued further. The gynecologic pathologies are then subdivided into the three primary locations: ovarian, tubal, and uterine. The different clinical conditions appropriate for each organ are then discussed. The basic science material for the week is then taught, using the scheme as a framework 
presentation scheme involves distinguishing between pelvis masses that have a gynecologic basis, and those that do not (Fig. 1). The gynecologic masses are then divided into those involving pathology of the ovary, the uterine tube, and the uterus itself. Each of these categories has subcategories associated with it. Although the final decision as to the nature of the pelvic mass is based on its histopathology, ultrasound (as well as CT and MRI images) can be very helpful in distinguishing the nature of the pathology available. Moreover, the images derived from ultrasound can help the student place the different disease entities into clinicallyappropriate categories while working through the clinical presentation scheme. Of course, the pedagogical utility of ultrasound mimics its role in clinical diagnosis and treatment. For example, Figure 2 illustrates a case of polycystic ovaries, a representative nonneoplastic pelvic mass. Figures $3 \mathrm{~A}$ and $\mathrm{B}$ illustrate a normal uterine cavity scanned by threedimensional and color Doppler ultrasound. ${ }^{6}$ Figure 4 demonstrates an invasive endometrial cancer. Figure 5 demonstrates pathology of the uterine tube. Figures 6 and 7 illustrate a malignancy of the ovary. The placement of such figures in the context of the clinical presentation scheme along with the accompanying basic and clinical science constitutes a very powerful pedagogical approach to the study of medicine.

\section{OTHER WAYS IN WHICH ULTRASOUND CAN BE USEFUL IN STUDYING BASIC MEDICAL SCIENCES}

Ultrasound can also be used to study the physiological state of appropriate organs. Power Doppler ultrasound can be especially useful in studying the vasculature. ${ }^{7,8}$ For example, Figure 4 demonstrates how power Doppler studies of the uterus can indicate deep myometrial invasion by a malignancy. Since many cancers are highly vascularized due to angioneogenesis, color and power Doppler studies can help elucidate the status of malignant tumors compared to benign ones (Figs 6 and 7).

\section{ULTRASOUND AS A MEANS OF LEARNING HUMAN ANATOMY BY MEDICAL STUDENTS}

Of course, the ideal situation is to have the capability to perform three-dimensional ultrasound in the laboratory/ medical skills setting. This permits the students to have real-time investigatory capabilities of studying the human body in a manner that approximates the clinical setting. In

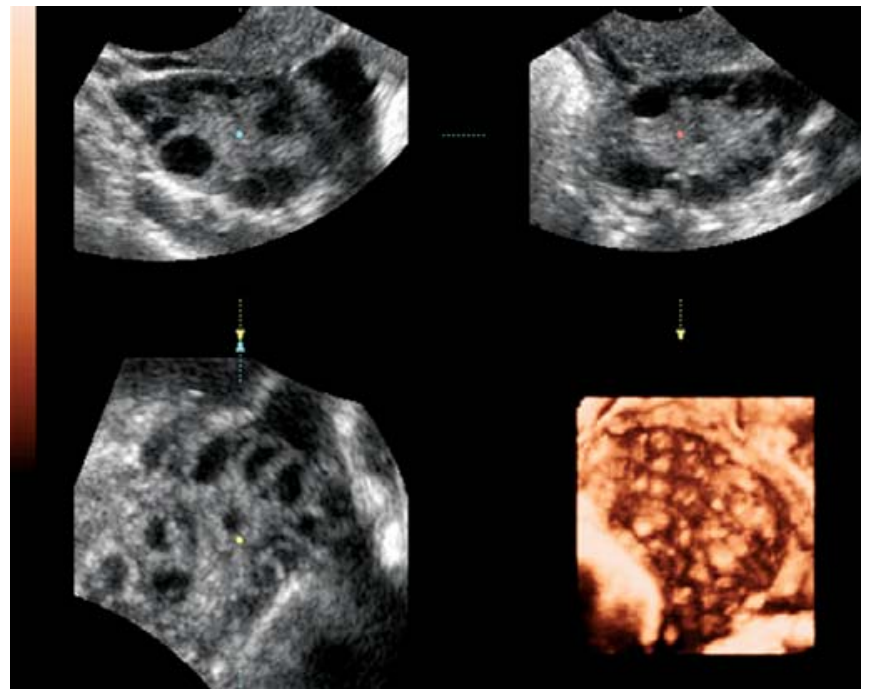

Fig. 2: Comparison of two-dimensional and three-dimensional (lower right panel) images of a polycystic ovary. Note the immediate visual impact of the three-dimensional image compared to the other twodimensional images. In our scheme on pelvic mass, polycystic ovaries represent a non-neoplastic ovarian mass

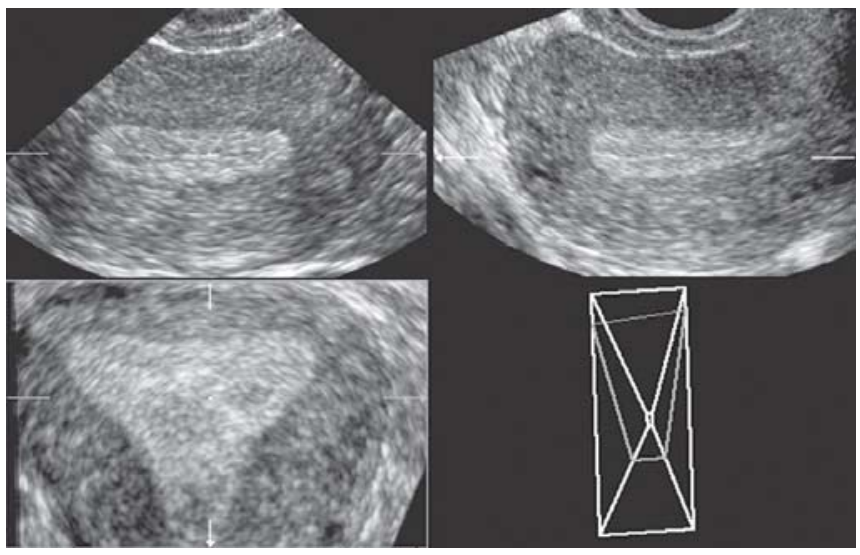

Fig. 3A: Three-dimensional ultrasound of the normal uterine cavity. Note the triangular shape of the uterine cavity in frontal reformatted section (lower left image)

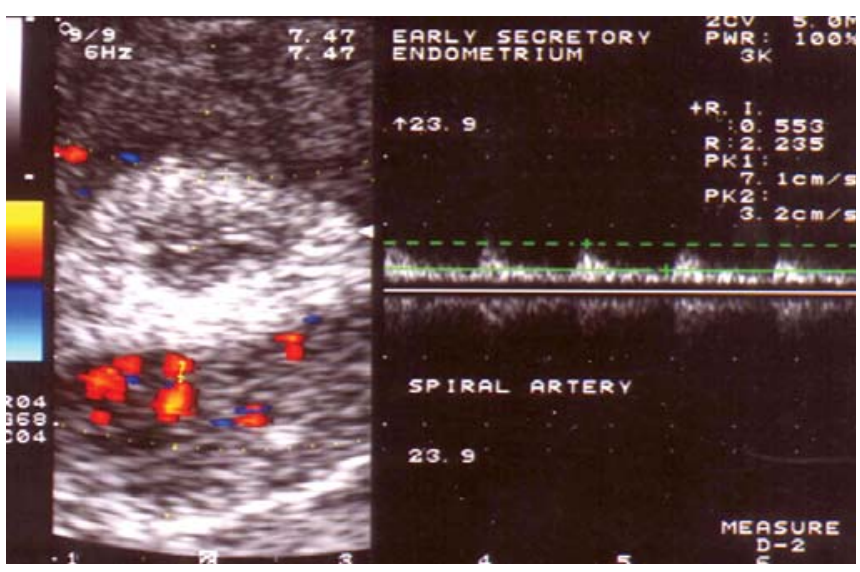

Fig. 3B: Color Doppler imaging of the endometrial vessels during the luteal phase of the menstrual cycle 


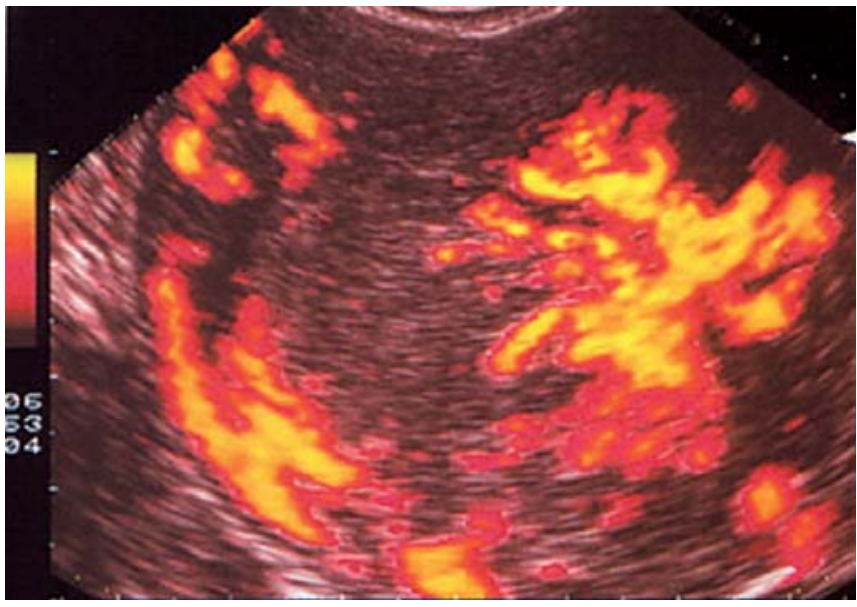

Fig. 4: Power Dopper imaging of the randomly dispersed vessels in a patient with advanced endometrial carcinoma. The irregular course of the vessels detected within the myometrium suggests deep invasion of the myometrium by the carcinoma. Histopathological studies following surgery confirmed this hypothesis. In our scheme, this condition is a representative of a neoplastic uterine mass

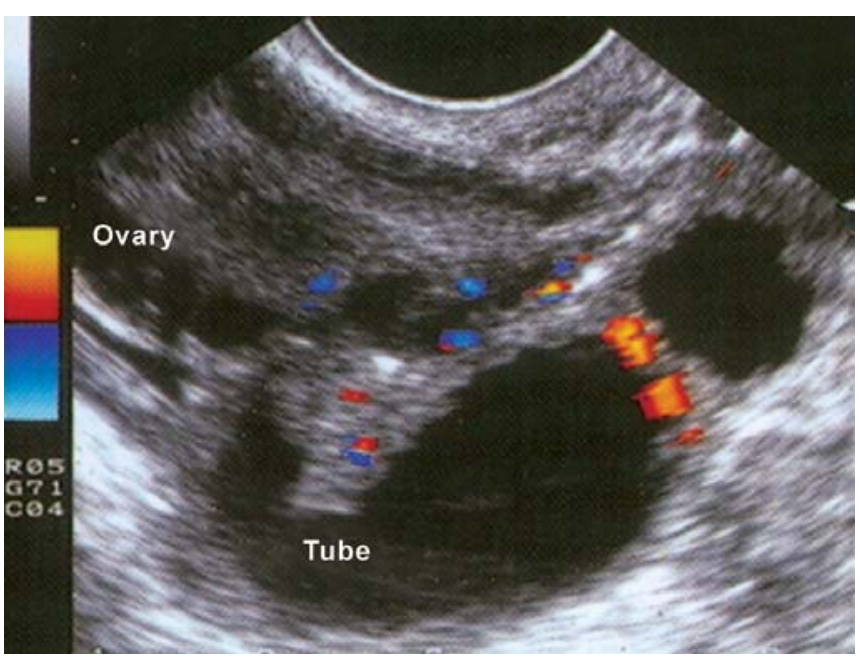

Fig. 5: Transvaginal sonogram of a complex adnexal mass containing a folded dilated tube and attached ovary. Note the presence of highly vascular thick septa and pseudosepta. This is an example of a nonneoplastic adnexal mass

addition to its powerful effects in motivating interest in the structure of the human body, ultrasound offers a very effective complement to cadaver dissection. By using transabdominal ultrasound for example, students can correlate the structures observed with the anatomy of their cadaveric specimens. This process can greatly facilitate attaining the ideal of having a three-dimensional appreciation for the structure of the human body. ${ }^{9}$ Such a mental picture will remain in the memory long after the details of the finer points of human anatomy have become forgotten through disuse.

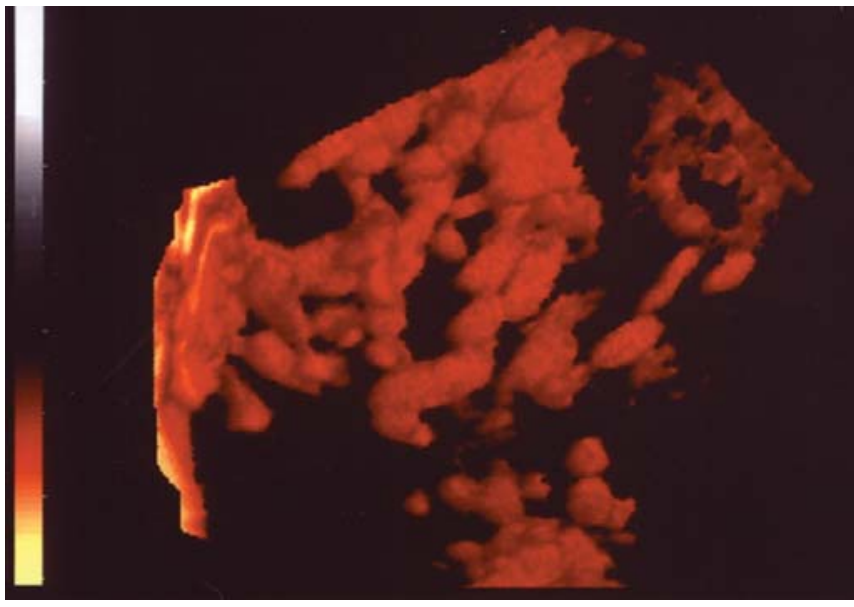

Fig. 6: Transvaginal three-dimensional power Doppler scan of a neoplastic ovarian mass. Note the irregular branching patterns of the blood vessels

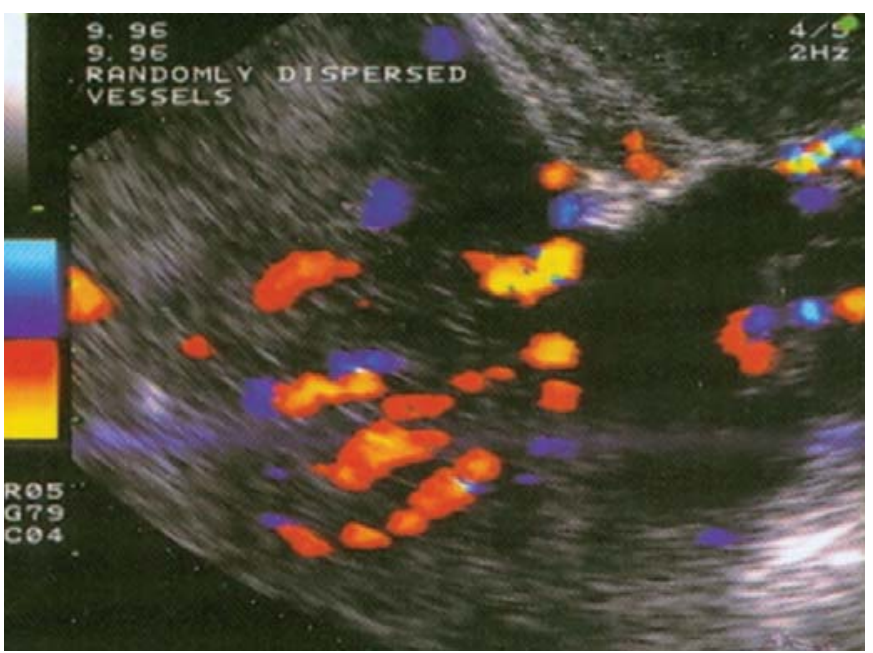

Fig. 7: Transvaginal color Doppler scan of a large ovarian tumor with echogenic contents. Color Doppler imaging demonstrates the presence of randomly dispersed irregular vessels that are pathognomonic for ovarian malignancy

\section{REFERENCES}

1. Bernard GR, Black A Jr. Methods for Learning Gross Anatomy: Eight Years' Experience in a Totally Problem-Based Curriculum. In: Problem-Based Study as an Educational Strategy. Bouhuijs PAJ, Schmidt HG, van Berkel HJM (Eds). Network Publications, Maastricht, Netherlands 1993;191-98.

2. Mandin H, Harasym P, Eagle C, Watanabe M. Developing a "Clinical Presentation" curriculum at the University of Calgary. Acad Med 1995;70:186-93.

3. Thomas M, Van Voorhis BJ. Gynecologic ultrasound. In: Gibbs RS, Karlan BY, Haney AF, Nygaard I (Eds). Danforth's Obstetrics and Gynecology (10th ed). Lippincott, Williams and Wilkins, Philadelphia 2008;540-54. 
4. Levi CS, Lyons EA, Holt SC, Dashefsky SM. Normal anatomy of the female pelvis and transvaginal sonography. Chapter 26 in: Callen PW (Ed). Ultrasonography in Obstetrics and Gynecology (5th ed). Sanders, Philadelphia 2007;887-917.

5. Kupesic S, Kurjak A, Bjelos D. Three- and Four-Dimensional Ultrasound in Human Reproduction. In: Kurjak A, Jackson D (Eds). An Atlas of Three- and Four-Dimensional Sonography in Obstetrics and Gynecology. Taylor and Francis, London, 2004;19-38.

6. Kupesic S, Kurjak A, Bjelos D. Ultrasound of the uterus. Chapter 46 in: Kurjak A, Chervenak F (Eds). Donald School Textbook of Ultrasound in Obstetrics and Gynecology. Parthenon Publishing Group, New York 2003;593-609.
7. Breyer B. Understanding Technology: The Key to Correct Diagnostics. Chapter 1 in: Kurjak A, Chervenak F (Eds). Donald School Textbook of Ultrasound in Obstetrics and Gynecology. Parthenon Publishing Group, New York 2003;3-21.

8. Kurjak A, Kupesic S, Breyer B. Transvaginal three-dimensional power Doppler ultrasound in gynecology and obstetrics. Chapter 27 in: Kurjak A, Kupesic S (Eds). An Atlas of Transvaginal Color Doppler (2nd ed). Parthenon Publishing Group, New York 2000;245-53.

9. Woloschuk W, Mandin H, Harasym P, Lorscheider F, Brandt L. Retention of basic science knowledge: A comparison between body system-based and clinical presentation curricula. Thinking and Learning in Medicine 2004;16(2):116-22. 